\title{
THE INCIDENCE OF SUGARS IN THE URINE OF INFANTS AND GHILDREN
}

\author{
BY \\ M. FIKRI, B.Sc., M.B., B.CH., \\ AND \\ MAH. A. EL-SAYED, M.B., B.Сн. \\ (From the Pædiatric Department, Faculty of Medicine, Cairo.)
}

The testing of urines of infants and children for reducing substances is often neglected, owing to difficulties in obtaining specimens of urine, particularly in infants, and to the rarity of diabetes in children.

For the purposes of this investigation, specimens of urine from 150 children, aged 2 months to 5 years, healthy and diseased (other than recognized diabetes), were examined for reducing substances both by Fehling's and Benedict's methods. Three specimens, taken on three successive days, were thus examined, and when a reducing substance was detected, the nature of the sugar was determined by the phenyl-hydrazine test. A sugar tolerance curve was made in the cases which showed the presence of glucose in the urine.

Of the apparently healthy children, numbering 63 , one case only, that of a girl 4 months old, breast-fed, showed a reducing substance in the urine, which proved to be lactose. Its appearance was only transient, as succeeding specimens of urine were negative.

Of the diseased children, numbering 87 , eleven or 12.5 per cent. showed the presence of a reducing substance in the urine. In all the eleven cases, the reducing substance was lactose, and in three glucose as well was detected in the urine.

Of the eight children who showed lactose only in the urine, five showed the presence of this substance to be only occasional, as succeeding examinations gave negative results. In three instances the excretion of lactose persisted; these were cases of Pott's disease, multiple boils, and pulmonary tuberculosis. The last two were purely breast-fed, the first was fed on the breast as well as animal milk.

The three cases that showed the presence of both lactose and glucose in the urine were of interest. One of them, a girl 8 months old, died on the same day and no sugar tolerance test was done. In the other two cases, 
both female infants of 9 and 6 months of age, a sugar tolerance curve was made, on a dose of glucose equal to $1 \mathrm{grm}$. per kgrm. of body weight given per os. The curves as shown in Fig. 1 and 2 demonstrate the features characteristic of diabetes mellitus. The history of these two infants showed that for some months past, they were wasting with no apparent cause. Both were purely breast-fed. One was admitted with a diagnosis of marasmus of doubtful origin, and died on the fifth day. Post-mortem examination showed broncho-pneumonia in both lungs, but no other lesion of importance. The other case was also admitted with a diagnosis of marasmus and bronchopneumonia. She also died on the fourth day, and post mortem nothing of importance was found, except the lesions in the lungs.
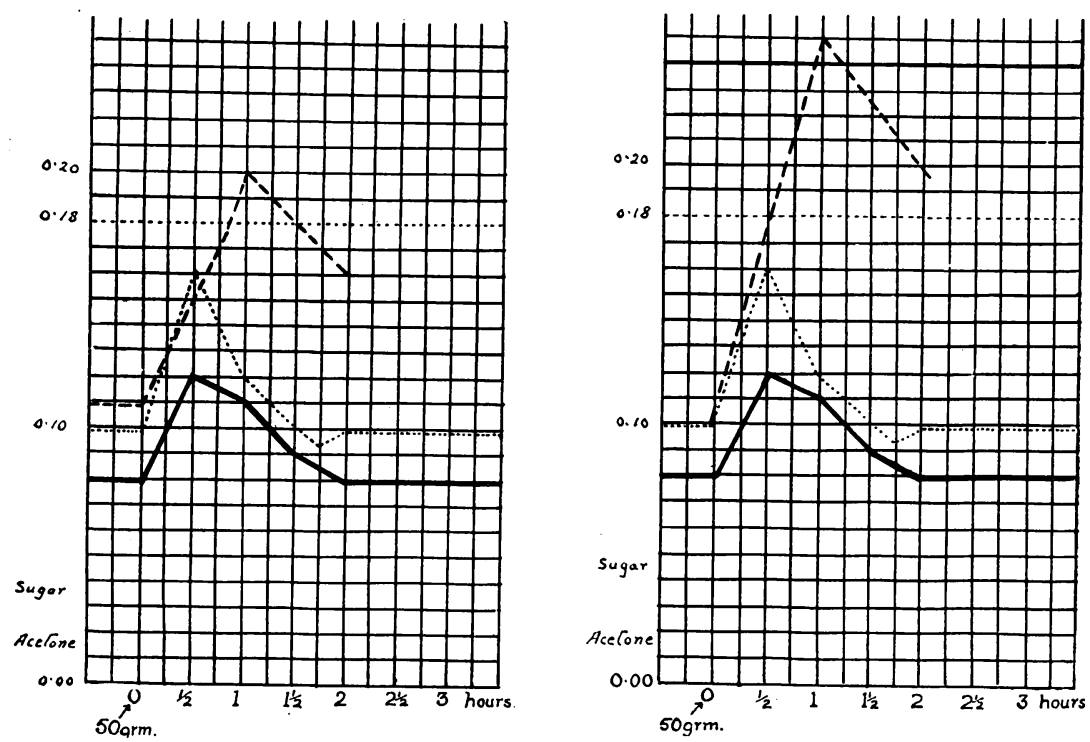

Figrers 1 and 2.-Sugar tolerance curves.

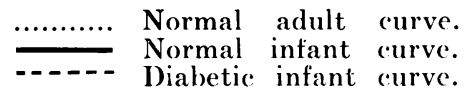

Discussion.-(1) Lactose can be passed occasionally in the urine of infants and children, even in health, but more frequently in disease, such as severe disturbances of the digestive tract and infections. It can be distinguished from glucose by the phenyl-hydrazine test, and by the fact that its presence in the urine is usually only occasional.

(2) Glucose when detected in the urine of infants and children is suggestive of diabetes. A sugar-tolerance test will confirm the diagnosis.

(3) Diabetes should be considered as a possible ætiological cause of marasmus in infants, 


\section{The normal sugar tolerance curve in infants}

For the purposes of the preceding investigation, an attempt was made to determine the characters of the sugar-tolerance curve in infancy and early childhood. The test was carried out on 14 normally developing children, whose ages varied from 5 to 18 months. In each an estimation of the fasting sugar, the maximum rise, the time for that rise to take place and the fall to normal, were determined. The dose of glucose given for the purposes of this test was $1 \mathrm{grm}$. per $\mathrm{kgrm}$. of body weight, dissolved in a little water. In no case did glucose appear in the urine. Fig. 3 shows the sugar-tolerance curve constructed on the average of figures obtained from this investigation.

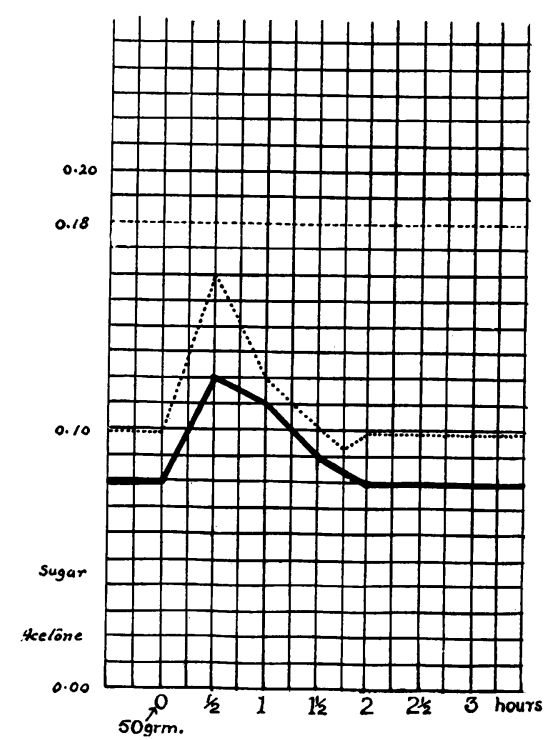

FIG. 3.-Sugar tolerance curve in infants.

Normal adult curve.

Normal infant curve.

Discussion.-(1) The fasting sugar varied from 0.074 to 0.118 , with an average of 0.094 per cent. This figure, perhaps, does not represent the true fasting level because some of the children were being breast-fed before the test.

(2) The average maximum rise was 0.032 per cent., and occurred in the large majority of the cases (in 65 per cent.) in the first half hour.

(3) The time of fall to fasting level was $1 \frac{1}{2}$ hours in the large majority of the cases.

(4) The average blood sugar after two hours was 0.081 per cent., which is lower than the original fasting level.

(5) The curve in general points to a condition of increased carbohydrate tolerance. 
REFERENCES.

Allen, F. M., Glycosuria and Diabetes.

Brown, M. J., Quart. J. Med., Oxford, 1925, XVIII, 175.

Corley, R. C., J. Biol. Chem., Baltimore, 1929, LXXXI, 541.

Fries, M. E., \& Kohn, J. L., Am. J. Med. Sci., Philad., 1925, CLXX, 547.

Spence, J. C., Quart. J. Med., Oxford, 1920-21, XIV, 314.

Tisdall, F. F., Drake, T. G. H., \& Brown, A., Am. J. Dis. Child., Chicago, 1925, XXX. 829. 